Alesia M. McManus, RUSA President, 2016-17

Alesia M. McManus is Environmental Sciences Librarian, Peter J. Shields Library, University of California, Davis; email:alemcmanus@ucdavis.edu.
A s I start my year as RUSA President, I would like to share my thoughts on the health and vitality of RUSA as we move into a new year with aspirational ideas, goals, and plans. RUSA is only as strong as the number of its engaged members. At the time of writing this column (May 2016), we have seen a decline in membership of 4.0 percent from last year. The decline from this same time the previous year (May 2015) was 2.8 percent. The RUSA budget relies significantly on membership dues for revenue and, while we're expecting our deficit to be lower than planned, we are operating with a deficit budget. As a result, in addition to possibly putting a dues increase on the 2017 ballot, we are talking about how to re-energize RUSA so we can operate nimbly and flexibly to support and encourage the greatest possible member engagement.

Our new strategic plan, which Anne Houston discussed in her President's column in the Fall 2015 issue of RUSQ, focuses on how we provide value to our members. In particular, our vivid description of the future we desire for RUSA reflects the importance of providing professional learning resources. Goal \#l of the strategic plan is to "offer services, programs and products that maximize the value of membership, making RUSA a good return on investment for its members and encouraging member engagement, recruitment and retention," and one of the objectives related this goal is to "develop and expand educational resources and experiences that are of high value to many members." A key action item this past year was to review the Learning Opportunities and Knowledge Coordination Task Force (LOKCS) report which recommended ways to improve RUSA's support of members' professional learning.

LOKCS established a definition for Continuing Learning as "self-directed learning throughout a member's career to obtain knowledge, learn new skills, and stay up-to-date using multiple methodologies." Key highlights of the report include:

- Promulgating a statement of vision and values for continuing learning

- Strengthening RUSA's organization and communication

- Building a framework for learning

- Focusing efforts on online and added value opportunities

- Enhancing RUSA's bottom line

In the interests for furthering the aims of the report, I am sharing here the vision statement and values for RUSA's continuous learning. 


\section{VISION STATEMENT}

RUSA members work in and for an international learning community characterized by a culture committed to sharing knowledge, expertise, and experience to benefit the diverse populations they serve. RUSA nurtures learning opportunities and dialogue on timely, relevant, and thought-provoking ideas and knowledge by generating and disseminating professional standards and guidelines, publications, online continuing education opportunities, and conference programming. RUSA creates opportunities for members to translate new ideas into successful practice.

RUSA empowers entrepreneurial members, committees, and sections to create responsive, engaging learning opportunities that anticipate professional development needs of members and others engaged in information service. As an organization, RUSA encourages coordinated, recombinant use of RUSA-generated information and knowledge. A collateral benefit of these efforts is educational programming that generates a dependable revenue stream to allow RUSA to carry out its mission. ${ }^{2}$

\section{VALUE STATEMENT}

The Reference and User Services Association's continuing learning services embody the values of:

- RELEVANCE-Learning experiences respond to and anticipate information services practitioners' needs.

- QUALITY-Learning experiences provide value to participants in their work.
- RESPONSIVENESS-Member input guides the ongoing assessment and improvement of RUSA learning experiences.

- COST EFFECTIVENESS - Affordably priced learning opportunities generate revenue RUSA can reinvest in its member priorities.

- ENGAGEMENT-Members create opportunities to share expertise, exchange ideas on issues, and benefit from active learning experiences.

The RUSA Executive Committee and Board will integrate the LOKCS recommendations into our strategic plan action items for the upcoming year. I welcome your comments and feedback on this RUSA initiative. Please send an email message to alemcmanus@ucdavis.edu.

I would like to acknowledge the excellent efforts of the LOKCS task force members: Elizabeth German, Sarah Hammill, Michael Hermann, Todd Hines, Shannon Jones (co-chair), Elizabeth Kline, Emily Kornak, Carolyn Larson, Mary Parker, Jeannette Pierce, Mary Pagliero Popp (co-chair), Jenny Presnell, and James Rettig.

\section{Notes}

1. Continuing education offerings serve as a primary source of revenue in the RUSA budget, so providing more robust and relevant offerings could be beneficial to the health of RUSA as a division and well as providing a valuable benefit to the membership.

2. The RUSA Board reviewed and commented upon the Vision and Values Statements for Continuing Learning at its May 15, 2015 meeting. 